\author{
Marquette University \\ e-Publications@Marquette
}

College of Nursing Faculty Research and

Publications

Nursing, College of

2013

\title{
Fit Into College II: Physical Activity and Nutrition Behavior Effectiveness and Programming Recommendations
}

\author{
Kristi M. King \\ University of Louisville \\ Jiying Ling \\ University of Louisville \\ S. Lee Ridner \\ University of Louisville \\ Dean E. Jacks \\ Hanover College \\ Karen S. Newton \\ University of Louisville
}

See next page for additional authors

Follow this and additional works at: https://epublications.marquette.edu/nursing_fac

Part of the Nursing Commons

\section{Recommended Citation}

King, Kristi M.; Ling, Jiying; Ridner, S. Lee; Jacks, Dean E.; Newton, Karen S.; and Topp, Robert V., "Fit Into College II: Physical Activity and Nutrition Behavior Effectiveness and Programming Recommendations" (2013). College of Nursing Faculty Research and Publications. 276.

https://epublications.marquette.edu/nursing_fac/276 
Authors

Kristi M. King, Jiying Ling, S. Lee Ridner, Dean E. Jacks, Karen S. Newton, and Robert V. Topp

This article is available at e-Publications@Marquette: https://epublications.marquette.edu/nursing_fac/276 


\title{
Fit Into College II: Physical Activity and Nutrition Behavior Effectiveness and Programming Recommendations
}

\author{
Kristi McClary King, Jiying Ling, Lee Ridner, \\ Dean Jacks, Karen S. Newton, and Robert Topp
}

\begin{abstract}
Purpose: To determine whether residency (living on campus versus off campus) was related to the effects of Fit into College on students' health behaviors, and to understand interns' perceptions of their roles in mentoring their trainees. Design: Pre-experimental, one-group, pretest-posttest design and a posttest focus group interview. Setting: University-offered health and internship courses. Subjects: Twenty-four students (trainees) participated in the intervention, nine of whom lived on campus. Five student-interns served as their mentors. Intervention: Fit into College was a 14-week intervention in which trainees teamed up with an intern to improve and/or maintain healthy nutrition and physical activity behaviors. Measures: Trainees' nutrition and physical activity behaviors and perceptions were quantitatively assessed through surveys at preintervention and postintervention. Interns' mentoring perceptions were qualitatively assessed through a focus group interview after the intervention. Analysis: Two-factor repeated measure ANOVAs and qualitative theme identification. Results: Regardless of their residency location, the trainees' perceptions of the health benefits of eating fruits and vegetables improved during the intervention. However, for trainees living on campus, the intervention was not effective in increasing the number of fruits and vegetables consumed or the planning for food preparation. The interns perceived that they did not have adequate access to healthy foods, the knowledge or skills to prepare healthy foods, or the competency to teach food preparation strategies to their trainees. For trainees living on campus, the intervention was more effective in decreasing perceived exercise barriers than trainees living off campus. Conclusion: Future iterations of Fit into College may focus on 1) improving college students' planning and preparation of healthy foods, 2) segmenting trainees into more homogeneous groups for the interns to tailor their areas of expertise (campus vs. off-campus and/or freshman vs. upperclass students), and 3) collaborating with university-partners to improve environmental conditions to promote physical activity and healthy nutrition.
\end{abstract}

Keywords: college students, physical activity, nutrition, residence halls

\footnotetext{
King is with the Dept. of Health and Sport Sciences, University of Louisville, Louisville, KY. Ling and Ridner are with the School of Nursing, University of Louisville, Louisville, KY. Jacks is with the Dept. of Kinesiology and Integrative Physiology, Hanover College, Hanover, IN. Newton is with the Dept. of Campus Health Promotion, University of Louisville, Louisville, KY. Topp is with the College of Nursing, Marquette University, Milwaukee, WI.
} 
The overweight and obesity rates among Americans have escalated from $12.0 \%$ in 1991-36.0\% in 2004 and are estimated to continue to rise (Mokdad et al., 1999; Ogden, Carroll, Curtin et al., 2006). Sedentary lifestyles and poor dietary habits are key predictors of this national epidemic (Odgen et al., 2006). Research results repeatedly tout the efficacy of physical activity and nutrition interventions in attenuating the overweight and obesity crisis (Dietz \& Robinson, 2005; Odgen et al., 2006; Stevens et al., 2007; Troiano, 2000; United States Department of Health and Human Services, 1996) and have been deemed as leading health indicators for improving our nation's health (Healthy People 2020, 2011).

Among the college student population, the overweight and obesity trends have similarly increased from $20.5 \%$ in $1995-32.4 \%$ in 2011 (American College Health Association, 2011). This increase is reflected in the dietary and physical activity habits of college students. Only $6.2 \%$ of college students $(6.5 \%$ female and $5.4 \%$ male) consumed the recommended five or more fruits and vegetables per day (American College Health Association, 2010), and approximately onefifth of students $(19.2 \% ; 21.4 \%$ male and $17.9 \%$ female) met the public health recommendation of engaging in 30 minutes or more of moderate intensity physical activity 5 or more days per week (American College Health Association, 2010; Haskell et al., 2007). Colleges provide a unique setting in which students have the opportunity to both live and learn on campus, thus underscoring the significance that health promotion programs and policies can have in enhancing and supporting students' health.

\section{Background}

Ecological models of health behavior posit that an individual's health behaviors are influenced by his or her surroundings (Broffenbrenner, 1979; Glanz, Rimer, \& Viswanath, 2008; McLeroy, Bibeau, Steckler, \& Glanz, 1988; Sallis \& Owen, 2002). Since college students may spend the majority of their time within the campus' social and physical environments and are subject to eating campus-served foods and engaging in campus-housed physical activity, it behooves health researchers to address the individual, social, and environmental factors that positively or negatively influence students' health behaviors. Interventions that support students' ability to "fit into college" can mitigate the growing overweight and obesity epidemic by fostering healthy lifestyles.

Fit into College is a healthy behavior promotion intervention in which undergraduate students, otherwise known as "trainees," team up with a senior-level "intern" to improve and/or maintain their nutrition and physical activity behaviors, thus maximizing the trainees' likelihood to "fit into college" (Topp et al., 2011). Interns mentor their trainees (usually two trainees per intern) weekly to discuss nutrition and fitness principles and motivational strategies (individual-level support); provide coaching and counseling from the trainees' previous week and goal-setting for the upcoming week (social-level support); and exercise with the trainees in campus fitness facilities and dine in the campus restaurants (environmental-level support). See Table 1 for a description of the weekly cognitive and behavioral objectives to improve trainees' health.

Based on the Transtheoretical Model (TTM), the Fit into College intervention was designed to address the cognitive and behavioral aspects of health behavior 


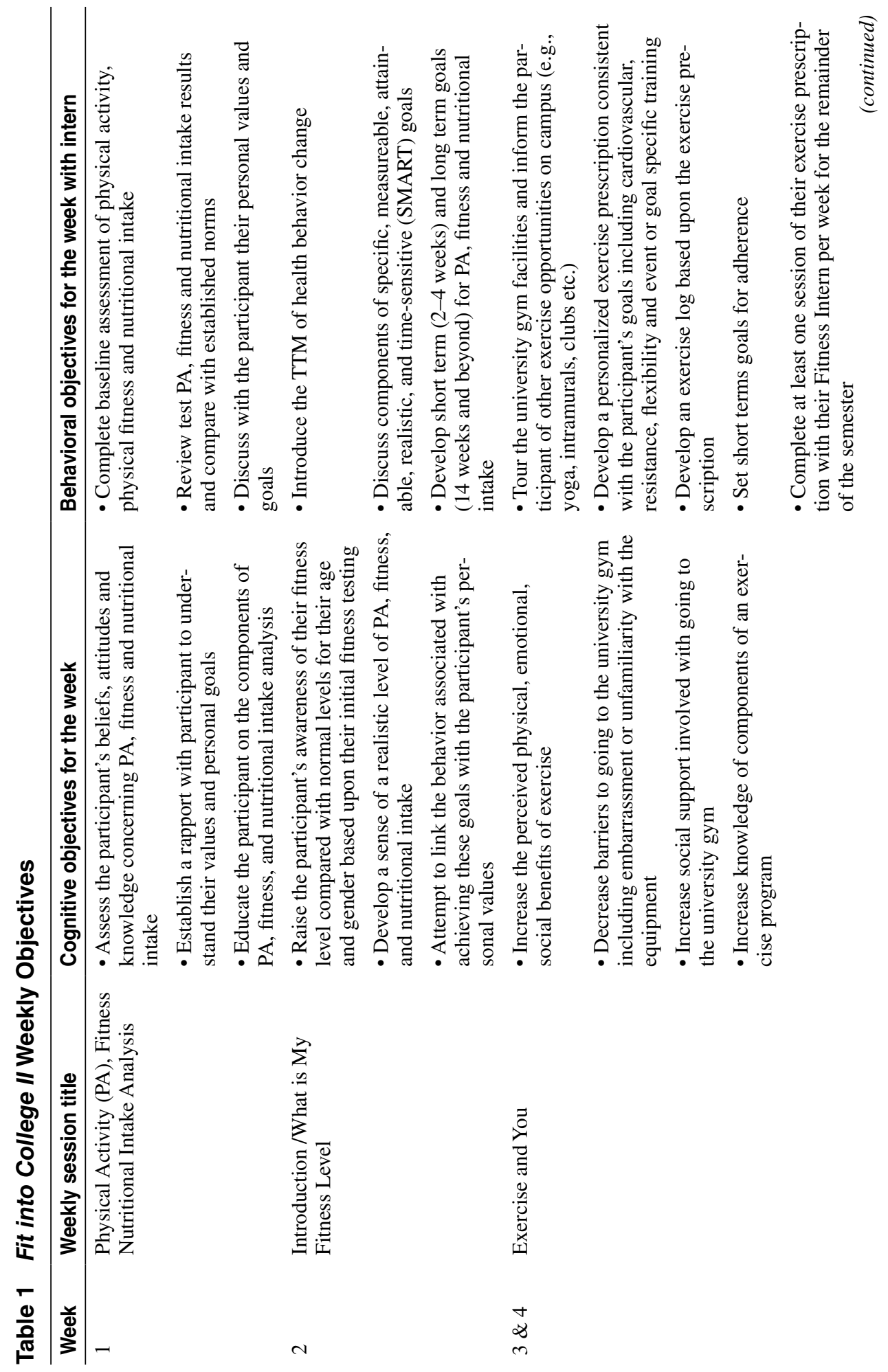




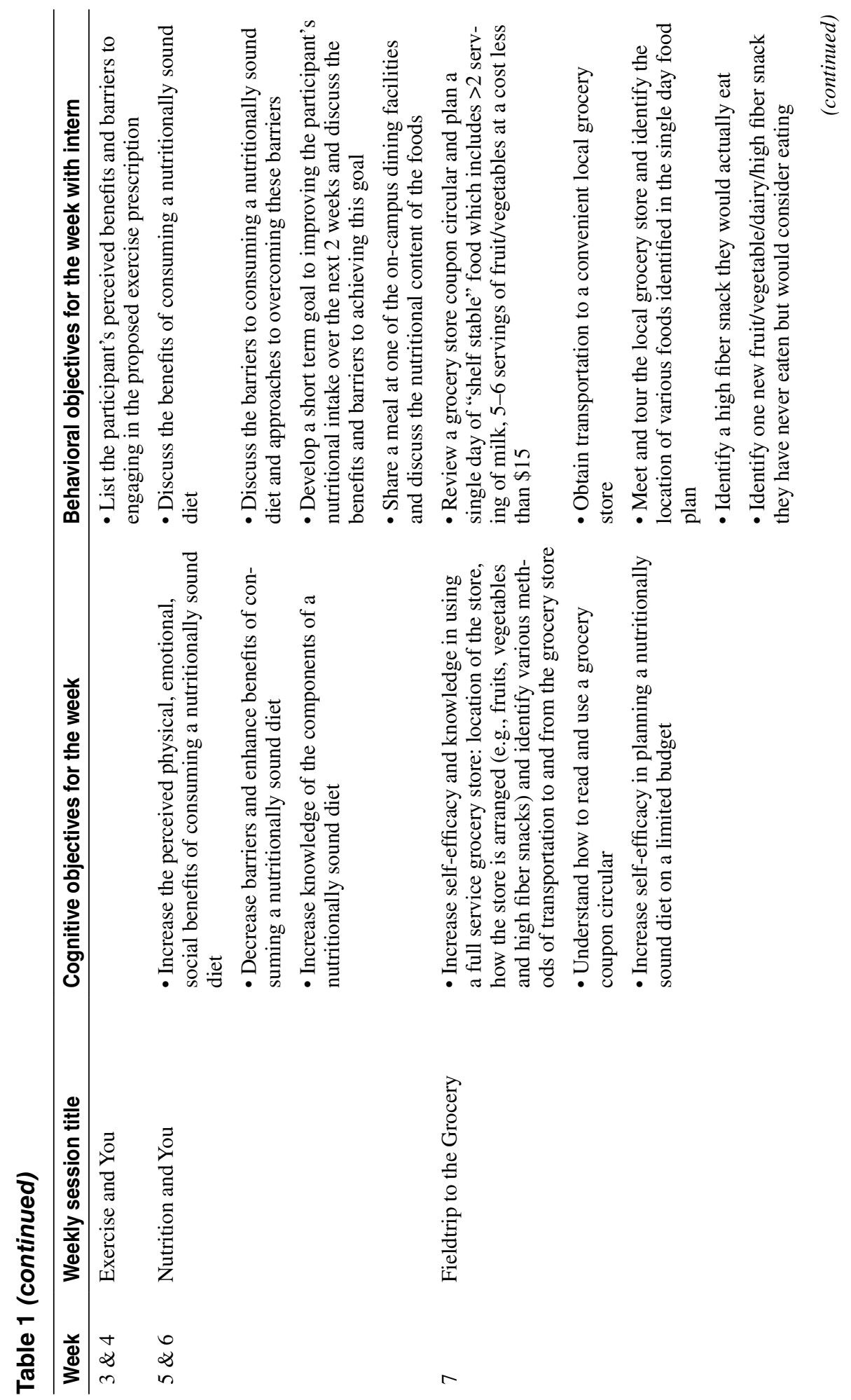




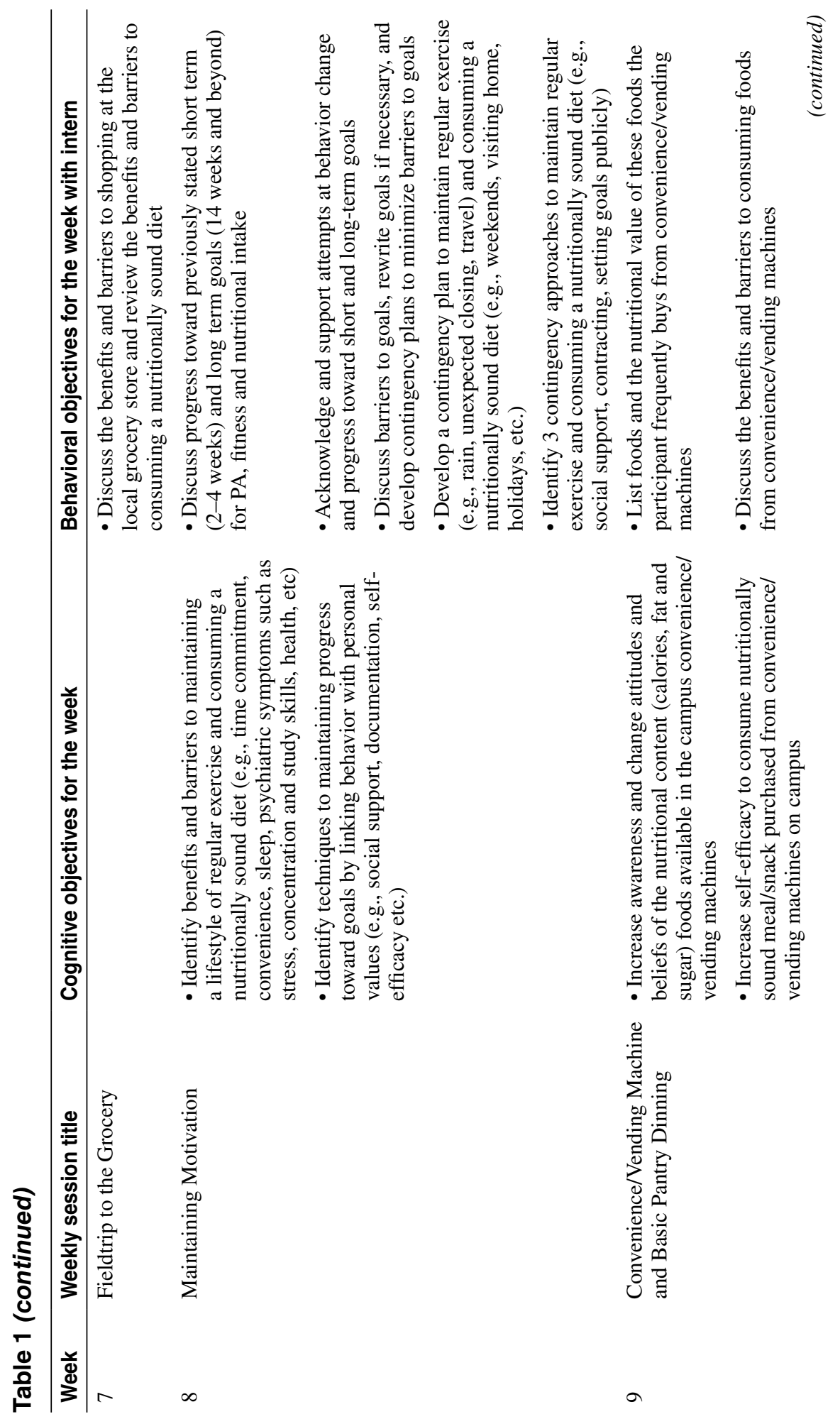




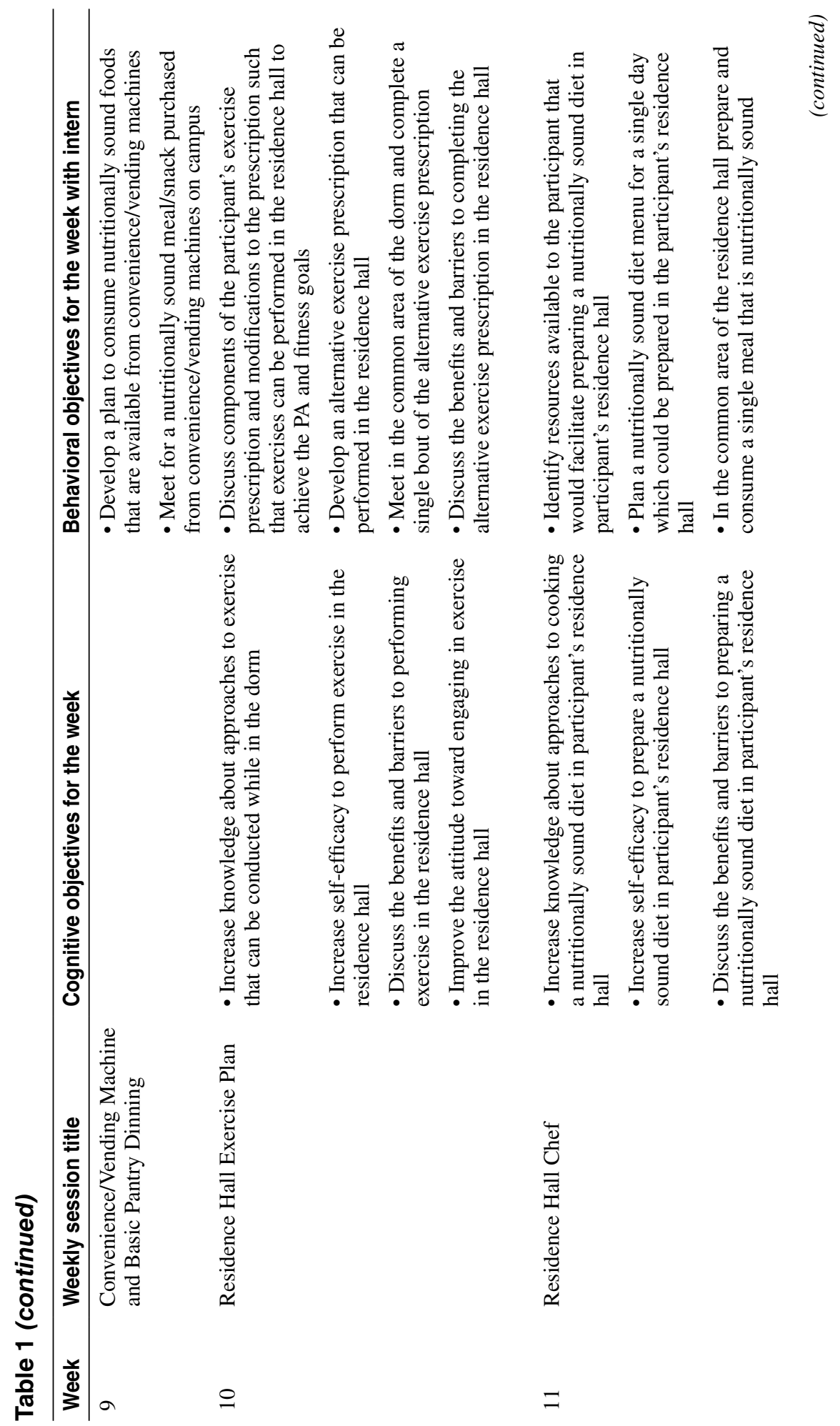




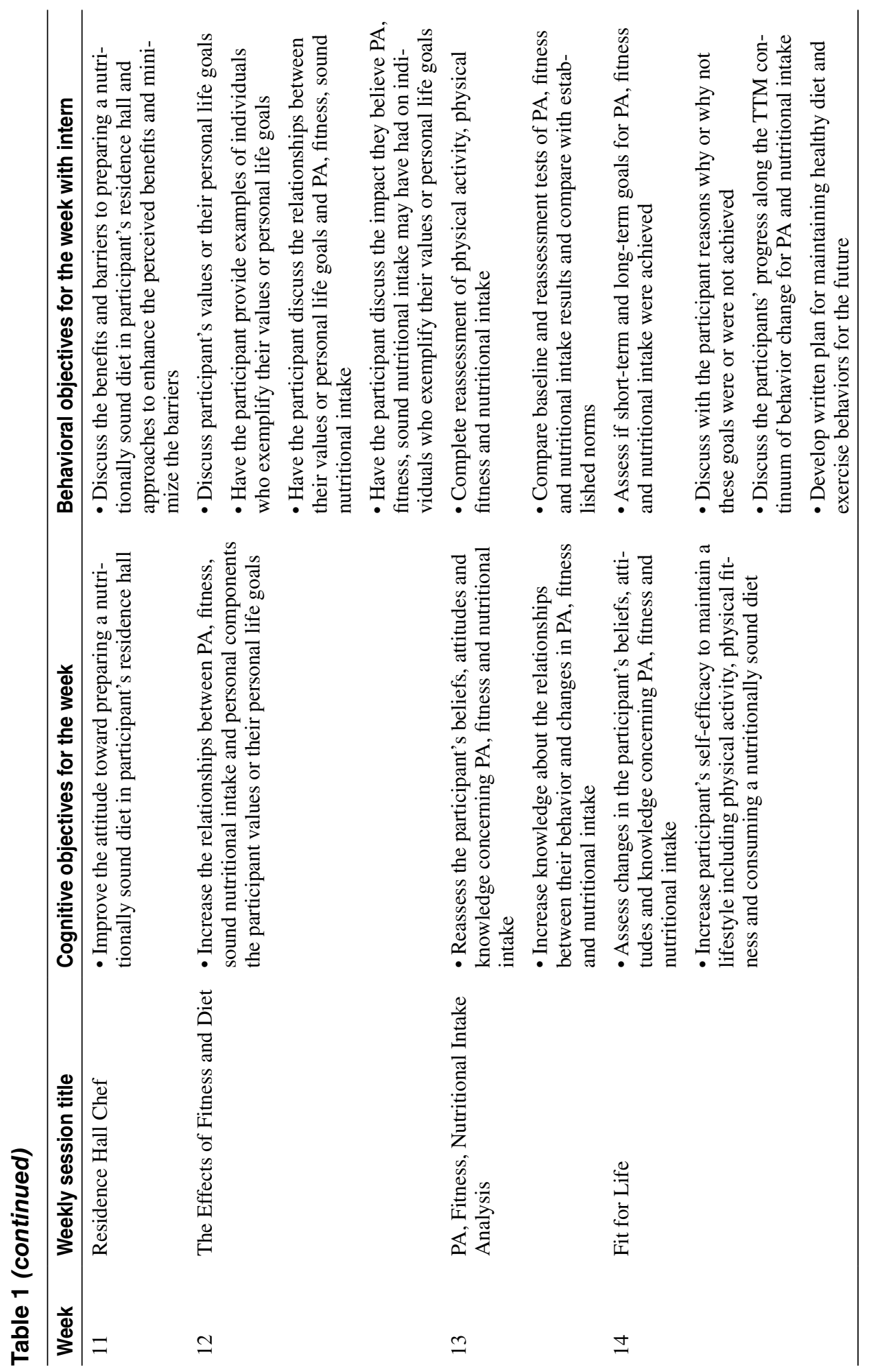


change (Prochaska \& Velicer, 1997; Topp et al., 2011). The TTM has been widely used in various health behaviors promotion studies, such as smoking cessation, physical activity and healthy eating (Marshall \& Biddle, 2001; Prochaska \& Velicer, 1997). Preliminary findings from the Fit into College I 10-week intervention showed successes in improving campus-residing, freshmen college students' health behaviors and outcomes (Topp et al., 2011). For the current study, 14-week Fit into College II, participant recruitment was broadened to include any undergraduate student living on or off campus. Considering the differences in students' access to healthy foods and physical activity opportunities that residency may present, it is important to explore the influence of residency on intervention results. For example, students who live off campus may or may not have convenient or affordable access to healthy foods or exercise facilities. And, although students who live on campus may have access to readily available foods and exercise facilities, barriers may be present within the college environment that influence students' access to healthy options. Therefore, the purposes of this current study were 1) to determine whether residency (living on campus versus off campus) was related to the effects of Fit into College II on students' health behaviors, and 2) to understand interns' perceptions of their roles in mentoring their trainees. Results from this study may provide information for future obesity prevention intervention designs among college students.

\section{Methods}

\section{Sample}

Before participant recruitment, the University Institutional Review Board approved two separate study protocol—one protocol outlining the data collection procedures involving the trainees enrolled in the Fit into College II intervention and the second protocol involving the interns enrolled in their senior-level internship course. Trainees were recruited from one healthy lifestyles class in which the intervention was conducted, and interns were recruited from one senior-level internship course. Trainees' and interns' instructors were not present during recruitment or data collection and were not notified as to which students participated in the study (as to not influence their course grade). Participants were explained the nature of the study and voluntarily signed the informed consent.

The average age of the trainees who participated in the study $[n=26 ; 15$ females $(57.7 \%), 11$ males $(42.3 \%)$ ] was 20.2 years (range 18-25) with 7 of the 14 freshmen and 1 of the 12 upperclassmen living on campus. The mean age of the interns ( $n=5 ; 2$ females, 3 males) was 24.2 years (range 21-33), and all were full-time, health and sport sciences major students, and lived off campus.

\section{Data Collection Procedures}

This study used trainees' pre- and postintervention quantitative data and interns' postintervention qualitative data. The quantitative data were obtained at baseline and following the 14-week intervention from the trainees. The interns participated in a semistructured, open-ended format, focus group interview session (Patton, 2002). The session was digitally recorded to ensure reliability and transferability for transcription and content analysis. 


\section{Outcome Measures}

For trainees, moderate intensity physical activity, vigorous intensity physical activity, walking and sedentary behavior were measured using the International Physical Activity Questionnaire (Craig et al., 2003), and exercise pros and cons were measured using the Exercise Decisional Balance Scale (Nigg, Rossi, Norman, \& Benisovich, 1998). Exercise Decisional Balance is a two-factor, 10-item Likert-type scale using a five-point scale $(1=$ extremely important to $5=$ not important $)$. The coefficient of Cronbach's alpha has been reported to be 0.83 and 0.71 for benefits and barriers respectively (Paxton et al., 2008). Calculation of the Cronbach's alpha of the scale in this study yielded an alpha of 0.87 and 0.82 for benefits and barriers respectively.

Previous day numbers of fruits and vegetables were measured through a twentyfour hour intake record, and perceived health benefits, convenience, preparation, planning, and barriers of consuming fruits and vegetables were measured using the Fruit and Vegetables Decisional Balance Scale (Henry, Reimer, Smith, \& Reicks, 2006). Fruits and Vegetables Decisional Balance is a five factor (health benefits-pros, general barriers-cons, convenience issues-cons, planning issues-pros, and preparation issues-pros) measurement using a five-point scale ( $1=$ not important at all to $5=$ extremely important). It has been reported to have a good internal reliability with Cronbach's alpha coefficient ranging from 0.61-0.81 (Henry, Reimer, Smith, \& Reicks, 2006). In this current study, the coefficients of Cronbach's alpha were 0.76 for health benefits-pros, 0.51 for general barriers-cons, 0.51 for convenience issues-cons, 0.54 for planning issues-pros, and 0.72 for preparation issues-pros.

\section{Data Analysis}

A series of two-way repeated measure ANOVAs were developed to determine the main effect and interaction effect of the intervention and residency on trainees' health behaviors. The 12 physical activity and nutrition variables (moderate physical activity, vigorous physical activity, walking, sedentary behavior, previous day number of fruits and vegetables consumed, perceived health benefits, convenience, preparation, planning, and barriers of consuming fruits and vegetables, exercise pros, and exercise cons) served as dependent variables. In each repeated measure ANOVA, there was one between-subject variable (residency: living on campus vs. off campus), one within-subject variable (intervention: preintervention vs. postintervention), and one interaction variable (residency * intervention). A significance value of $\alpha=.05$ was set for analyses in this study. The focus group interview recording was transcribed verbatim, and themes were identified within the data using inductive coding methods (Patton, 2002).

\section{Results}

\section{Trainees' Quantitative Results}

The results of the repeated measure ANOVA revealed significant interaction effects of the intervention and residency on previous day number of fruits and vegetables $(F=5.02, p<0.05)$, perceived fruit and vegetable planning $(F=7.63, p<.01)$ and 
exercise barriers $(F=11.49, p<.01)$; therefore, the within-subject main effects of the intervention were interpreted based on residency. The significant interaction results indicated that the effects of intervention on trainees' previous day number of fruits and vegetables, perceived fruit and vegetable planning and exercise barriers depended on the residency of the trainees. An inspection of group means revealed that previous day number of fruits and vegetables decreased from preintervention $(M=3.50)$ to postintervention $(M=1.14)$ for trainees who lived on campus. Further, there was a decreasing trend on their perceived fruit and vegetable planning after intervention though not statistically significant $(M=16.38$ vs. $M=14.00)$. The exercise barriers for trainees living on campus decreased significantly from 22.75 to $19.50(p<.01)$ while the exercise barriers for trainees living off campus did not decrease significantly. After the intervention, trainees living on campus perceived fewer exercise barriers compared with trainees living off campus ( $M=19.50 \mathrm{vs}$. $M=23.39, p<.05)$.

There were no significant interaction effects on other outcome variables, thus the main effects can be freely interpreted. Significant main effects were detected in two intervention variables: sedentary behaviors $(F=6.764, p<.05)$ and perceived fruits and vegetables' health benefits $(F=32.00, p<.01)$. After the intervention, trainees were more sedentary $(M=184.79$ vs. $M=326.86)$ and the trainees' perceived health benefits increased from preintervention $(M=31.57)$ to postintervention $(M=66.31)$.

\section{Interns' Qualitative Results}

Planning, Preparing, and Accessing Healthy Foods. The interns conveyed that the trainees would have preferred more guidance on planning and preparing healthy meals in their residence hall rooms where they had access to a kitchen. However, one intern indicated that she "didn't want to cook because [she] worked late and had to study afterwards." Another intern indicated that "it takes so much time and energy really, if you think about it-to prepare [healthy foods]." Furthermore, all interns felt compelled to eat the university food since they were required to purchase a mandatory meal plan, regardless of campus residence or not. The interns ". . . tried to go over what was better choices [at a campus] buffet . . . . We went to [campus fast-food restaurant] . . . and talked about the options they have."

Home Exercising. Some trainees were intimidated to exercise in the campus fitness center despite their interns showing them how to use the equipment and exercising with them. The interns acknowledged their trainees' hesitation and were able to share home exercise programs with their trainees. One intern recalled "I print off like exercises that you get from like Self Magazine . . . those little workouts and things .... We would do those together and that was fun so they had something to do at home."

Targeting Students. One intern, who was also an intern the previous year, indicated that the intervention had expanded too quickly. According to him, "taking seniors and juniors made a big difference" in a negative way. Another intern agreed stating "Yeah, mine [trainees] were all upper class. Two were seniors and they had all had nutrition and they had gone through a lot of the classes so I was just 
trying to get them to incorporate it into their life. They knew a lot of the things I was telling them." She further indicated that "They had heard it all. They just didn't care to do it."

\section{Discussion}

Regardless of their residency location, the trainees' perceived health benefits of eating fruits and vegetables improved during the intervention. However, for trainees living on campus, the intervention was not effective in increasing the number of fruits and vegetables consumed and fruits and vegetables planning. An interesting theme emerged from the interns' focus group session and warrants additional discussion. The interns perceived that they did not have adequate access to healthy foods nor did they have the knowledge or skills to prepare healthy foods. Further, they felt they were not competent in teaching food preparation strategies to their trainees. Thus, interns' lack of knowledge and skills on food preparation may result in the ineffectiveness of the intervention in increasing trainees' fruits and vegetables consumption.

For trainees living on campus, the intervention seemed to be more effective on decreasing perceived exercise barriers than trainees living off campus. This may be due to the convenient access to exercise facilities for trainees living on campus. Interestingly, the interns indicated that some trainees still preferred to exercise in their residence hall rooms, even though university provided them with exercise facilities.

After the intervention, the trainees, regardless of residency, were more sedentary and showed no significant increase on moderate, vigorous activity and walking. Since this intervention occurred in the fall semester (August through December), the increase in sedentary behaviors may be attributed to students' increase in studying time for final exams, or the onset of colder weather thus decreasing students' engagement in outdoor physical activities. Further, some trainees were intimidated to exercise in the campus fitness center despite their interns showing them how to use the equipment and exercising with them.

In this study, students' access to healthy foods and exercise facilities were environmental factors that hinged upon institutional policies. According to ecological theories of health behavior (McLeroy et al., 1988), these institutional, community, or public policies can influence student's health behaviors. Therefore, policies should be targeted intervention areas in which faculty and students can identify and implement healthy alternatives on and off campus.

Lastly, regarding the interns' perceptions of their roles in mentoring their trainees, the interns expressed their desire to offer Fit into College to freshman only, as it was offered the first year of the intervention. They thought that targeting a specific group would help achieve the overall goal of "fitting into college." Since social support was qualitatively identified as a key component for the interns to effectively mentor their trainees, the interns felt that including freshmen-only would help build a more homogenous group.

The findings of this study however, may not be generalizable to other groups of college students since this study consisted of a small, self-selected sample of students enrolled in a university-offered health course. In addition, social desirability 
may have limited their responses during the interviews. Further studies should include a larger, randomly selected sample and a comparison group.

\section{Conclusions and Recommendations}

As universities strive to improve environmental conditions that facilitate healthy behaviors, the results of this study clearly underscore the importance of fostering students' knowledge, attitudes, and skills as well as cultivating social support. A university-wide ecological approach to health promotion (Sallis \& Owen, 2002), that focuses on individual, social, and environmental factors, can be an effective strategy for attenuating the overweight and obesity epidemic among students. Future iterations of Fit into College may focus on 1) improving college students' planning and preparation of healthy foods, 2) segmenting trainees into more homogeneous groups for the interns to tailor their areas of expertise (campus vs. off-campus and/or freshman vs. upperclass students), and 3) collaborating with university-partners to improve environmental conditions to promote physical activity and healthy nutrition.

\section{References}

American College Health Association. (2010). American College Health AssociationNational College Health Assessment II: Spring 2010 reference group executive summary. MD: Linthicum.

American College Health Association. (2011). National College Health Assessment II: Reference group executive summary spring 2011. Hanover, MD: American College Health Association.

Broffenbrenner, U. (1979). The ecology of human development. Cambridge: Harvard University Press.

Craig, C.L., Marshall, A.L., Sjostrom, M., Bauman, A.E., Booth, M.L., Ainsworth, B.E., . . . Oja, P. (2003). International physical activity questionnaire: 12-country reliablity and validity. Medicine and Science in Sports and Exercise, 35(8), 1381-1395. doi:10.1249/01.MSS.0000078924.61453.FB

Dietz, W.H., \& Robinson, T.N. (2005). Overweight children and adolescents. The New England Journal of Medicine, 352(20), 2100-2109. doi:10.1056/NEJMcp043052

Glanz, K., Rimer, B.K., \& Viswanath, K. (Eds.). (2008). Health behavior and health education: Theory, research, and practice (4th ed.). San Francisco: Jossey-Bass.

Haskell, W.L., Lee, I-M., Pate, R.R., Powell, K.E., Blair, S.N., Franklin, B.A., . . Bauman, A. (2007). Physical activity and public health: Updated recommendation for adults from the American College of Sports Medicine and the American Heart Association. Medicine and Science in Sports and Exercise, 39(8), 1423-1434. doi:10.1249/ mss.0b013e3180616b27

Healthy People 2020. (2011). Healthy People 2020. Retrieved on January 31, 2011, from http://www.healthypeople.gov/hp2020/

Henry, H., Reimer, K., Smith, C., \& Reicks, M. (2006). Associations of decisional balance, processes of change, and self-efficacy with stages of change for increased fruit and vegetable intake among low-income, African-American mothers. Journal of the American Dietetic Association, 106, 841-849. doi:10.1016/j.jada.2006.03.012

Marshall, S.J., \& Biddle, S.J.H. (2001). The transtheoretical model of behavior change: A meta-analysis of applications to physical activity and exercise. Annals of Behavioral Medicine, 23(4), 229-246. doi:10.1207/S15324796ABM2304_2 
McLeroy, K.R., Bibeau, D., Steckler, A., \& Glanz, K. (1988). An ecological perspective on health promotion programs. Health Education Quarterly, 15, 351-377. doi:10.1177/109019818801500401

Mokdad, A.H., Serdula, M.K., Dietz, W.H., Bowman, B.A., Marks, J.S., \& Koplan, J.P. (1999). The spread of the obesity epidemic in the United States, 1991-1998. Journal of the American Medical Association, 282(16), 1519-1522. doi:10.1001/jama.282.16.1519

Nigg, C.R., Rossi, J.S., Norman, G.J., \& Benisovich, S.V. (1998). Structure of decisional balance for exercise adoption. Annals of Behavioral Medicine, 20, s211.

Ogden, C.L., Carroll, M.D., Curtin, L.R., McDowell, M.A., Tabak, C.J., \& Felgal, K.M. (2006). Prevalence of overweight and obesity in the United States, 1999-2004. Journal of the American Medical Association, 295(13), 1549-1555. doi:10.1001/jama.295.13.1549

Patton, M.Q. (2002). Qualitative research \& evaluation methods (3rd ed.). Thousand Oaks: Sage Publications.

Paxton, R.J., Nigg, C.R., Motl, R.W., McGee, K., McCurdy, D., Matthai, C.H., \& Dishman, R.K. (2008). Are constructs of the transtheoretical model for physical activity measured equivalently between sexes, age groups, and ethnicities? Annals of Behavioral Medicine, 35(3), 308-318. doi:10.1007/s12160-008-9035-x

Prochaska, J.O., \& Velicer, W.F. (1997). The Transtheoretical Model of health behavior change. American Journal of Health Promotion, 12, 38-48. doi:10.4278/0890-117112.1.38

Sallis, J.F., \& Owen, N. (2002). Ecological models of health behavior. In K. Glanz, B.K. Rimer, \& F.M. Lewis (Eds.), Health behavior and health education: Theory, research, and practice (3rd ed.). San Francisco: Jossey-Bass.

Stevens, J., Murray, D.M., Baggett, C.D., Elder, J.P., Lohman, T.G., Lytle, L., . . Young, D.R. (2007). Objectively assessed associations between physical activity and body composition in middle-school girls. American Journal of Epidemiology, 166(11), 1298-1305. doi:10.1093/aje/kwm202

Topp, R.V., Edward, J.S., Ridner, S.L., Jacks, D.E., Newton, K., Keiffner, P., . . Conte, K.P. (2011). Fit into College: A program to improve physical activity and dietary intake lifestyles among college students. Recreational Sports Journal, 35, 69-78.

Troiano, R.P. (2000). Energy and fat intakes of children and adolescents in the United States: Data from the National Health and Nutrition Examination Surveys. The American Journal of Clinical Nutrition, 72(supplement), 1343-1353.

United States Department of Health and Human Services. (1996). Physical activity and health: A report of the Surgeon General. Atlanta, GA: Centers for Disease Control and Prevention, National Center for Chronic Disease Prevention and Health Promotion. 
Copyright of Recreational Sports Journal is the property of Human Kinetics Publishers, Inc. and its content may not be copied or emailed to multiple sites or posted to a listserv without the copyright holder's express written permission. However, users may print, download, or email articles for individual use. 